\title{
ANALISIS KADAR TIMBAL (Pb) PADA AIR YANG MELALUI SALURAN PIPA PENYALUR PERUSAHAAN DAERAH AIR MINUM (PDAM) MAKASSAR
}

\author{
Artati \\ Jurusan Analis Kesehatan Poltekkes Kemenkes Makassar \\ tatigiland@rocketmail.com
}

\begin{abstract}
ABSTRAK
Air merupakan kebutuhan pokok dalam kehidupan. Masyarakat kota Makassar pada khususnya menggunakan air PDAM sebagai sumber air minum dan kebutuhan lainnya. Air yang berasal dari PDAM menggunakan saluran pipa agar air dapat digunakan dalam kebutuhan rumah tangga. Banyak faktor yang mempengaruhi kualitas air pada sistem perpipaan, diantaranya adalah akibat logam berat. Penelitian ini bertujuan untuk mengetahui kandungan logam berat timbal $(\mathrm{Pb})$ pada air yang melalui saluran pipa penyalur Perusahaan Daerah Air Minum Kota(PDAM) Makassar. Jenis penelitian yang digunakan adalah Observasi Laboratorik. Jumlah populasi dalam peneliian ini adalah air dari saluran pipa penyalur PDAM kota Makassar, dan teknik pengambilan sampel dilakukan secara accidental sampling yaitu 5 air dari lokasi yang berbeda. Analisis sampel menggunakan metode Spektrofotometer Serapan Atom. Hasil penelitian menunjukkan bahwa Semua air yang diambil sebagai sampel mengandung timbal.Kadar yang diperoleh sangat kecil atau di bawah batas deteksi metode $(<0,01$ mg/l). Sesuai dengan Peraturan Pemerintah Menteri Kesehatan RI NO 492/MENKES/PER/2010 dimana kandungan Timbal dalam air yang diperbolehkan yakni $0,1 \mathrm{mg} / \mathrm{l}$ sehingga semua sampel yang diperiksa memenuhi syarat standar. Disarankan penelitian selanjutnya sebaiknya menggunakan juga air sumur atau bor untuk dibandingkan.
\end{abstract}

Kata kunci : Air Saluran Pipa PDAM, Timbal (Pb)

\section{PENDAHULUAN}

Air adalah suatu kebutuhan esensial manusia yang kedua setelah udara untuk keperluan hidupnya. Manusia hanya bisa bertahan hidup kurang lebih 3 hari tanpa air. Untuk meciptakan suatu lingkungan hidup manusia yang bersih dan sehat tanpa persediaan air yang cukup, mustahil akan terjadi. Persediaan air yang banyak dan dan kualitas yang lebih baik akan meningkatkan derajat kesehatan masyarakat. (Daud, 2005)

Masyarakat Indonesia pada umumnya dan kota Makassar pada khususnya menggunakan air PDAM sebagai sumber air minum dan kebutuhan lainnya. PDAM atau 
Perusahaan Daerah Air Minum adalah menyediakan air yang sudah melalui proses pengolahan, dimana pengolahan air bertujuan memberikan perlindungan pada sumber air dengan perbaikan kualitas asal air sampai kualitas yang diinginkan atau sesuai standar kualitas bagi Indonesia yaitu itu pada permenkes RI No.416/MENKES/Per/IX/1990 tentang syarat-syarat dan pengawasan kualitas air bersih.

Penggunaan air rumah tangga khususnya digunakan sebagai air minum, masak, mandi, dan mencuci harus tetap dijaga kualitas dan kuantitasnya. Sumber air dapat berasal dari sumber air tanah dan sungai, air yang berasal dari PAM (air ledeng) menggunakan saluran pipa agar air dapat digunakan dalam kebutuhan rumah tangga.

Banyak faktor yang mempengaruhi kualitas atau mutu air pada sistem berpipa yang dapat mengakibatkan kontaminasi mikroba atau kontaminasi kimia pada air. Bahan pembuatan dan pemasangan pipa serta pelapisan pipa pun dapat meningkatkan konsentrasi logam berat, misalnya timbal. Penelitian sebelumnya telah banyak yang membuktikan bahwa air dari saluran pipa yang berbahan besi mengandung timbal.

Bangsa Romawi pertama kali menggunakan timbal untuk membuat pipa air, beberapa di antaranya masih digunakan sampai sekarang. Penggunaan timbal lainnya juga pada pelapis kabel, pelekat pada pipa dan solder terutama pada produk yang harus tahan karat. Sebagai contoh, pipa timbal digunakan untuk pipa-pipa yang akan mengalirkan bahan kimia yang korosif, melapisi saluran tempat cucian yang sering mengalami kontak dengan bahan-bahan korosif.Timbal juga digunakan sebagai pelapis kabel listrik yang akan digunakan di dalam tanah atau di bawah permukaan air. (Anonim, 2015)

Timbal $(\mathrm{Pb})$ adalah bahan yang biasanya digunakan sebagai zat penghambat korosif pada pipa besi. $\mathrm{Pb}$ mudah terlepas dari saluran pipa disebabkan beberapa faktor seperti faktor lingkungan, jenis dan ketebalan pipa, umur atau lamanya pipa, tekanan, dan proses korosifikasi. Hal ini memungkinkan $\mathrm{Pb}$ akan bercampur dengan air yang mengalir di sepanjang pipa instalasi air khususnya dalam pipa air rumah tangga dan dapat berdampak buruk bagi kesehatan. (Anonim, 2015)

Timbal adalah logam yang bersifat toksik terhadap manusia, yang bisa berasal dari mengonsumsi makanan, minuman, atau melalui inhalasi dari udara, kontak langung lewat kulit, kontak lewat mata, dan lewat parenatal keracunan timbal dapat menyebabkan efek akut dan kronis. Gejala keracunan kronis ditandai oleh rasa mual, anemia, sakit pada bagian perut, dan dapat menyebabkan kelumpuhan. Keracunan timbal juga dapat mempengaruhi seperti sistem peredaran darah, sistem saraf, system urinaria, system reproduksi, system endokrin, dan jantung. (Palar, 2012)

Komplikasi akibat timbal ini bukan hanya pada sistem saraf saja tetapi juga pada tulang dan gigi. Akibat yang sangat menonjol pada gigi adalah karies (kekeroposan) gigi yang 
menyeluruh. Bahkan janin dalam kandungan ibu yang mengalami keracunan timbal ini mengalami karies gigi yang jauh lebih tinggi, ketulian (hearing loss) dan katarak. Kasus ini dialami oleh penduduk dari Bangka Belitung yang mengalami karies gigi yang hebat karena air minum disana mengandung timbal. (Anonim, 2015).

Berdasarkan uraian di atas, peneliti telah melakukan penelitian analisis kandungan timbal $(\mathrm{Pb})$ pada air yang melalui saluran pipa penyalur PDAM

\section{METODE}

Penelitian ini merupakan observasi laboratorik yang bersifat deskriptif dengan teknik analisis kuantitatif. Lokasi penelitian dilaksanakan di Balai Besar Laboratorium Kesehatan Makassar pada tanggal 20 Maret - 15 Mei 2017

Populasi dalam penelitian ini adalah air dari sumber air Perusahaan Daerah Air Minum (PDAM) Makassar. Sampel dalam penelitian ini adalah air saluran PDAM Ratulangi Makassar sebanyak 5 sampel dari air saluran PDAM Ratulangi Makassar dengan teknik pengambilan sampel dalam penelitian ini adalah accidental sampling.

Bahan yang digunakan adalah Asam Nitrat $\left(\mathrm{HNO}_{3}\right)$ pekat, larutan standar Timbal (Pb) 100 ppm, air suling (aquadest), dan sampel air pipa paralon. Sedangkan alat-alat yang digunakan adalah spektrofotometer serapan atom, beaker glas, erlenmeyer, pipet ukur, gelas ukur, labu ukur,dan, corong gelas,

\section{Pengumpulan Data}

Analisis menggunakan metode spektrofotometer serapan atom.

Prosedur Kerja

1. Wadah Pengambilan Sampel

Terbuat dari bahan yang tidak mempengaruhi sifat contoh air, mudah dicuci dari bekas contoh air sebelumnya. Contoh air mudh dipimdahkan ke dalam botol penampung atau wadah penyimpanan tanpa ada sisa bahan tersuspensi di dalamnya, mudah dan aman dibawa, mempunyai kapasitas 1-5 contoh air dan tidak menimbulkan reaksi kimia.

2. Cara Pengambilan Sampel

Menyiapkan alat dan bahan yang untuk mengambil sampel yang sesuai dengn keadaan sumber air. Wadah terlebih dahulu dibilas dengan sampel kemudian diisi dengan sampel yang akan diuji dan tutup dengan baik.

3. Bahan Pengawet Yang Dibutuhkan Dalam Pengambilan Air

Dalam pengambilan contoh air harus memperhatikan parameter yang akan diperiksa dan waktu pengiriman contoh air ke laboratorium. Bila pengiriman contoh air ke laboratorium melebihi standar waktu yang ditetapkan, maka contoh air harus ditambahkan bahan pengawet yang sesuai. Untuk sampel air bersih yakni 72 jam, untuk air yang tercemar yakni 48 jam, dan untuk air limbah yakni 12 jam. Adapun bahan pengawet air yaitu Asam sulfat, Natrium hidroksida, Toluol, Asam nitrit, dan Seng asetat 2 N. Pemakaiannya disesuaikan dengan contoh air yang akan diperiksa. 
4. Pemeriksaan Sampel

a. Analisa kualitatif logam timbal $(\mathrm{Pb})$

1. Larutan sampel ditambahkan asam sulfat encer, terbentuk endapan putih yang tidak larut jika ditambahkan berlebih, menunjukkan adanya timbal.

2. Larutan sampel ditambahkan ammonia terbentuk endapan putih, menunjukkan adanya timbal dalam sampel.

3. Larutan sampel ditambahkan $\mathrm{NaOH} 1 \mathrm{~N}$ terbentuk endapan Putih yang larut jika ditambahkan berlebih, menunjukkan adanya timbal dalam sampel.

4. Larutan sampel ditambahkan asam klorida encer tersebut endapan putih, endapan larut dalam $\mathrm{NH} 4 \mathrm{OH}$, menunjukkan adanya timba dalam sampel.

b. Analisa kuantitatif logam timbal $(\mathrm{Pb})$

1. Pembuatan larutan baku induk timbal (Pb) 1000 ppm

a). Larutan baku induk timbal $(\mathrm{Pb})$ Larutan baku induk timbal dibuat dari senyawa Timbal (II) nitrat $(\mathrm{Pb}(\mathrm{NO} 3) 2)$ sebanyak 0,1599 gram ditimbang secara seksama kemudian dimasukkan kedalam labu ukur $100 \mathrm{ml}$, dilarutkan dengan $7 \mathrm{ml}$ larutan asam nitrat pekat, setelah semuanya larut kemudian diencerkan dengan aquadest sampai tanda batas dan dikocok hingga homogen sehingga didapatkan larutan standar timbal 1000 ppm.
2.Pembuatan larutan deret standard timbal $(\mathrm{Pb})$, Dari larutan 1000 ppm dipipet $5 \mathrm{ml}$ dimasukkan dalam labu ukur $50 \mathrm{ml}$ (100 ppm ). Dari larutan 100 ppm lalu dipipet 5 $\mathrm{ml}$ ke dalam labu ukur $100 \mathrm{ml}$ dan dicukupkan volumenya dengan air suling hingga $100 \mathrm{ml}$ (5 ppm). Lalu dari larutan 5 ppm dipipet masingmasing sebanyak $1 \mathrm{ml}, 5 \mathrm{ml}, 10 \mathrm{ml}$, $15 \mathrm{ml}$, dan $20 \mathrm{ml}$ dimasukkan kedalam labu ukur 50ml sehingga diperoleh konsentrasi larutan 0,1 ppm, 0,5 ppm, 1 ppm, 1,5 ppm dan 2 ppm.

b). Pembuatan kurva baku timbal $(\mathrm{Pb})$ Ke dalam nyala udara Asetilen diaspirasikan air suling untuk menolkan alat. Berturut-turut diaspirasikan larutan deret standard plumbum dan chromium, masing-masing di ukur serapannya dari konsentrasi yang terkecil sampai ke konsentrasi yang besar yaitu mulai dari konsentrasi 0,1 ppm, 0,5 ppm, 1 ppm, 1,5 ppm sampai 2 ppm pada panjang gelombang maksimum untuk masing-masing dengan menggunakan lampu katoda rongga unsur yang di duga yaitu $\mathrm{Pb}$ dan Cr. Nilai serapan dari larutan deret standard tersebut dicatat. Kurva baku dibuat dengan cara memplotkan nilai serapannya terhadap konsentrasi larutan.

c). Pengukuran kadar tembaga Larutan sampel diukur serapannya pada panjang gelombang maksimum dengan lampu katoda tembaga. Nilai serapan masingmasing larutan dicatat. kemudian diplotkan ke kurva baku sehingga 
diperoleh konsentrasi logam yang dianalisis.

\section{Analisa Data}

Data yang diperoleh dianalisis secara tabulasi deskriptif dengan pemaparan hasil akhir penelitian secara narasi serta dilengkapi dengan pemaparan tabel hasil pemeriksaan.
Kesehatan Makassar yang dilaksanakan pada tanggal 20 Maret 15 Mei 2017, maka diperoleh hasil penelitian terhadap kandungan timbal $(\mathrm{Pb})$ pada air yang melalui saluran pipa penyalur PDAM Makassar metode Spektrofotometri Serapan Atom (SSA) ditunjukkan pada tabel berikut :

\section{HASIL}

Berdasarkan penelitian yang dilakukan di Balai Besar Laboratorium

Tabel 1. Hasil analisis kandungan timbal $(\mathrm{Pb})$ dengan Spektrofotometri Serapan Atom

\begin{tabular}{|c|c|c|c|}
\hline No. & Sampel ID & $\begin{array}{c}\text { Konsentrasi } \\
(\mathbf{p p m})\end{array}$ & Absorbansi \\
\hline 1 & Blanko & 0,000 & $-0,0012$ \\
\hline 2 & Standar 1 & 0,1000 & 0,0019 \\
\hline 3 & Standar 2 & 0,2000 & 0,0044 \\
\hline 4 & Standar 3 & 0,3000 & 0,0074 \\
\hline 5 & Standar 4 & 0,4000 & 0,0102 \\
\hline 6 & Standar 5 & 0,5000 & 0,0128 \\
\hline
\end{tabular}

Sumber : Data primer April 2017

Persamaan garis regresi linear :

$$
y=a+b x, y=-0,0010762+0,027971 x
$$

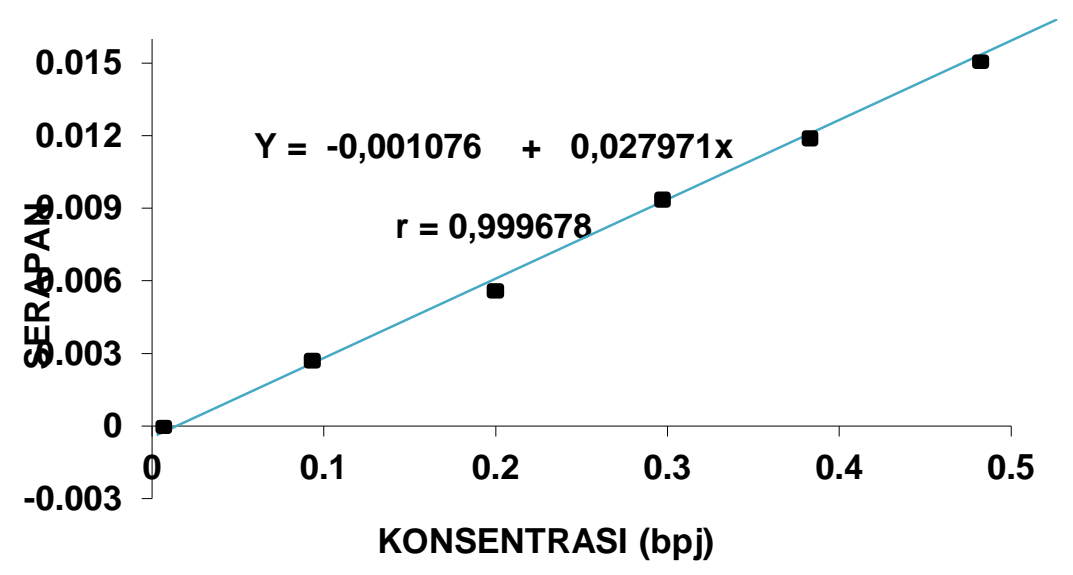


Gambar 1 Grafik Pengukuran Serapan Larutan Baku Standar Timbal (Pb) dengan Spektrofotometer Serapan Atom

Tabel 2 Kandungan timbal $(\mathrm{Pb})$ air yang melalui saluran pipa penyalur perusahaan daerah air minum (PDAM) Makassar

\begin{tabular}{|l|l|l|l|}
\hline $\begin{array}{l}\text { Kode } \\
\text { Sampel }\end{array}$ & Abs (y) & $\begin{array}{l}\text { Conc. }(\mathbf{x}) \\
\mathbf{p p m}\end{array}$ & $\begin{array}{l}\text { Kadar } \\
\text { Timbal } \\
\text { (ppm) }\end{array}$ \\
\hline A & -0.0688 & -0.0030 & $<0.01$ \\
\hline B & -0.0688 & -0.0030 & $<0.01$ \\
\hline C & -0.0724 & -0.0031 & $<0.01$ \\
\hline D & -0.0545 & -0.0026 & $<0.01$ \\
\hline E & -0.0581 & -0.0027 & $<0.01$ \\
\hline
\end{tabular}

Tabel 3 Data Sumber Air yang Melalui Saluran Pipa Penyalur Perusahaan Daerah Air Minum (PDAM) Makassar

\begin{tabular}{|c|l|}
\hline Kode Sampel & Sumber \\
\hline A & PDAM \\
\hline B & Banta-bantaeng \\
\hline C & Nuri \\
\hline D & Mariso \\
\hline E & Tupai \\
\hline
\end{tabular}

\section{PEMBAHASAN}

Analisis kadar Timbal $(\mathrm{Pb})$ pada air yang melalui saluran pipa penyalur Perusahan Daerah Air Minum (PDAM) kota Makassar yang digunaan masyarakat untuk kebutuhan sehari-hari dilakukan penelitian secara kuantitatif terhadap 5 (lima) sampel yang diambil secara Accidental Sampling. Dimana yang dijadikan sampel adalah air yang mengalir dari PDAM kota Makassar dari 5 wilayah yaitu PDAM, Bantabantaeng, Nuri, Mariso, Tupai
Pada proses preparasi sampel, hanya sampel air PDAM saja yang dilakukan destruksi basah. Sebanyak $50 \mathrm{ml}$ sampel air PDAM kemudian ditambahkan larutan $\mathrm{HNO}_{3}$ pekat sebanyak $10 \mathrm{ml}$. Fungsi penambahan $\mathrm{HNO}_{3}$ ini adalah untuk memisahkan timbal dari berbagai senyawa organik pada sampel. Senyawa timbal yang terpisah diikat oleh asam nitrat membentuk $\mathrm{Pb}$ nitrat sebagai senyawa yang mudah larut sehingga nantinya dapat ditentukan kadar timbal $\mathrm{Pb}$ dalam sampel. Setelah penambahan 
$\mathrm{HNO}_{3}$ sampel kemudian dipanaskan diatas hotplate secara perlahan sampai mendidih hingga asap berwarna kuning keluar sebanyak mungkin. Kemudian sampel didinginkan dengan tujuan agar semua gas $\mathrm{NO}_{2}$ hilang dan menguap. Lalu dilakukan penyaringan dengan menggunakan kertas Whatman no. 41 ke dalam labu ukur $50 \mathrm{ml}$ dengan tujuan untuk menghilangkan sisa-sisa lemak dan minyak yang dapat mengarbsorbsi logam timbal yang dianalisis. Setelah itu, dicukupkan volumenya dengan aquades hingga tanda batas sehingga didapatkan larutan hasil prepasi berwarna kuning jernih. Hasil larutan sampel tersebut kemudian diperiksa pada alat Spektrofotometer Serapan Atom (SSA) pada panjang gelombang 217 $\mathrm{nm}$.

Spektrofotometri merupaka
analitik yang terutama sekali digunakan untuk analisis logam dalam jumlah yang sangat kecil karena sangat peka. Prinsip kerja alat ini adalah berdasarkan pada penguapan larutan sampel kemudian logam yang terkandung di dalamnya diubah menjadi atom bebas. Atom tersebut mengarbsorbsi radiasi dari sumber cahaya yang akan dipancarkan dari lampu katoda yang mengandung unsur yang akan ditentukan. Banyaknya penyerapan radiasi kemudian diukur pada panjang gelombang tertentu. SSA dipilih dengan beberapa pertimbangan yakni metode SSA sangat cepat, selektif serta tingkat keakuratannya yang tinggi. Dikatakan cepat karena alat SSA ini dapat mengukur hingga 100 sampel dalam waktu satu jam, selektif karena dalam metode ini masing-masing unsur mempunyai karakteristik dalam menyerap energi dasar ke tingkat yang tereksitasi. Selain itu, hampir setiap atom yang terdapat dalam system periodik dapat diukur dengan menggunakan Spektrofotometer Serapan Atom (SSA).

Pada analisa kuantitatif, kadar unsur timbal $(\mathrm{Pb})$ dalam sampel diperoleh dari hasil ekstrapolasi serapan larutan sampel ke dalam kurva standar, yaitu dengan cara memasukkan serapan kedalam persamaan regresi yang didapat. Kadar Timbal $(\mathrm{Pb})$ dalam sampel belum melebihi dari nilai ambang yang diizinkan.

Ditemukannya kadar timbal dalam sampel dapat disebabkan oleh beberapa faktor seperti dari alam, penampungan suber air yang hampir sepenuhnya berbahan besi, juga pipa besi yang mejadi saluran pertama dari sumber penampungan. Selanjutnya dikhawatirkan akan terjadi akumulasi kandungan Timbal $(\mathrm{Pb})$ dalam tubuh dan dapat memberikan efek racun terhadap banyak fungsi organ yang terdapat dalam tubuh.

Berdasarkan hasil penelitian menunjukkan bahwa analisis kandungan timbal $(\mathrm{Pb})$ pada sampel air yang terlihat pada tabel 4.2 semua air yang diambil sebagai sampel mengandung timbal dengan kadar $<0,01 \mathrm{mg} / \mathrm{l}$ dimana kadar yang diperoleh sangat kecil atau di bawa batas deteksi metode $(<0,01 \mathrm{mg} / \mathrm{l})$. Sesuai dengan Peraturan Pemerintah Menteri Kesehatan RI NO 492/MENKES/PER/2010 dimana kandungan Timbal dalam air yang 
diperbolehkan yakni $0,1 \quad \mathrm{mg} / \mathrm{l}$ sehingga semua sampel yang diperiksa memenuhi syarat standar.

\section{KESIMPULAN}

Semua air yang diambil sebagai sampel mengandung timbal. Kadar yang diperoleh sangat kecil atau di bawah batas deteksi metode $(<0,01$ $\mathrm{mg} / \mathrm{l})$. Sesuai dengan Peraturan Pemerintah Menteri Kesehatan RI NO 492/MENKES/PER/2010 dimana kandungan Timbal dalam air yang diperbolehkan yakni $0,1 \quad \mathrm{mg} / \mathrm{l}$ sehingga semua sampel yang diperiksa memenuhi syarat standar.

\section{SARAN}

1. Bagi peneliti berikutnya diharapkan dapat meneliti lebih lanjut terhadap unsur-unsur logam yang lain.

2. Peneliti selanjutnya sebaiknya menggunakan juga air sumur atau bor untuk dibandingkan.

3. Bagi masyarakat, jika menggunakan air PDAM sebagai air minum sebaiknya dipanaskan hingga mendidih dan jika digunakan sebagai air bersih seperti mencuci dan mandi usahakan jangan tertelan.

\section{DAFTAR PUSTAKA}

Alhabsji, Syamsudin dan Soedjoto, 2001. Kedudukan dan Peranan Perusahaan Daerah dalam Pelaksanaan yang Nyata dan Bertanggungjawab.

Universitas Brawijaya. Jawa Timur

Brady Je., 2002. Kimia Universitas asas \& struktur .Tangerang: Binapura Askara
Daud Anwar, 2015 Penyediaan Air, Buku Ajaran Jurusan Kesehatan Lingkungan Univeritas Hasanuddin, Makassar

DEPKES, Peraturan Menteri Kesehatan R.I No.416/Permenkes/Per/IX/199 0, Tentang Syarat-Syarat dan Pengawasan Kualitas Air Bersih, Jakarta 1990

DEPKES, Peraturan Menteri Kesehatan R.I No.907/Permenkes/Per/VII/20 02, Tentang Syarat-Syarat dan Pengawasan Kualitas Air Minum, Jakarta, 2002

Effendi .F, Tresnaningsih. E, Sullistomo. AW, Wibowo .S, Hudoyo .S.K., Dariana. D, Setia. B, Argana. G, Pasolang. IS, Sari. A.D, Efendi. S, 2012 Penyakit Akibat Kerja Karena Logam Berat. Jakarta : Direktorat Bina Kesehatan Kerja dan Olah Kementrian Kesehatan Republik Indonesia

Gandjar, I.G., dan Rohman, A..2007. Kimia Farmasi Analisis. Yogyakarta:

Pustaka Pelajar.

Harmita, 2015. Analisi Fisikokimia : Potensiometri \& Spektroskopi, vol 1. Jakarta : Penerbit Buku Kedokteran EGC

Katzung .B.G, Masters, B.S., Trevor J.A., 2012. Farmakologi Dasar \& Klinik Vol. 2. Jakarta : PT. Rineka Cipta

Khopkar, S.M. 2003. Konsep Dasar Kimia Analitik. Jakarta. UIPress. 
Maemunah, Sri. 2004. Revitalisasi $B U M N$ dan BUMD . Lentera. Jakarta

Palar, H. 2012. Pencemaran dan Toksikologi Logam Berat. Jakarta: PT. Rineka Cipta

Rahman, Suryaningsih, Adi N. 2011, Kimia Analisis Air, Makassar : Politeknik Kesehatan Makassar Jurusan Analis Kesehatan

Ridhowati S., 2013. Mengenal Pencemaran Logam. Yogyakarta : Graha Ilmu

Syukri S., 1999. Kimia Dasar 3. Bandung : ITB

Vogel, A. I. 1985. Analisis Anorganik Kualitatif Makro dan Semimikro. Penterjemah: Sutiono, L., Hadyana, Pujaabmaka. Jakarta: Kalman Media Pustaka

Widowati, W, dkk. 2008. Efek Toksik Logam Pencegahan Dan Penanggulangan Pencemaran. Yogyakarta: Penerbit Andi.

Widyastuti P, Apriningsih, 2011, Pedoman Mutu Air Minum, Jakarta : EGC 